This item was submitted to Loughborough's Research Repository by the author.

Items in Figshare are protected by copyright, with all rights reserved, unless otherwise indicated.

\title{
Physical education teachers' continuing professional development in health- related exercise
}

PLEASE CITE THE PUBLISHED VERSION

http://www.tandfonline.com/doi/abs/10.1080/17408989.2011.594429

PUBLISHER

Taylor and Francis @ A Association for Physical Education

VERSION

AM (Accepted Manuscript)

LICENCE

CC BY-NC-ND 4.0

REPOSITORY RECORD

Cale, Lorraine, Laura Alfrey, and Louisa Webb. 2019. "Physical Education Teachers' Continuing Professional Development in Health-related Exercise”. figshare. https://hdl.handle.net/2134/11408. 
This item was submitted to Loughborough's Institutional Repository (https://dspace.lboro.ac.uk/) by the author and is made available under the following Creative Commons Licence conditions.

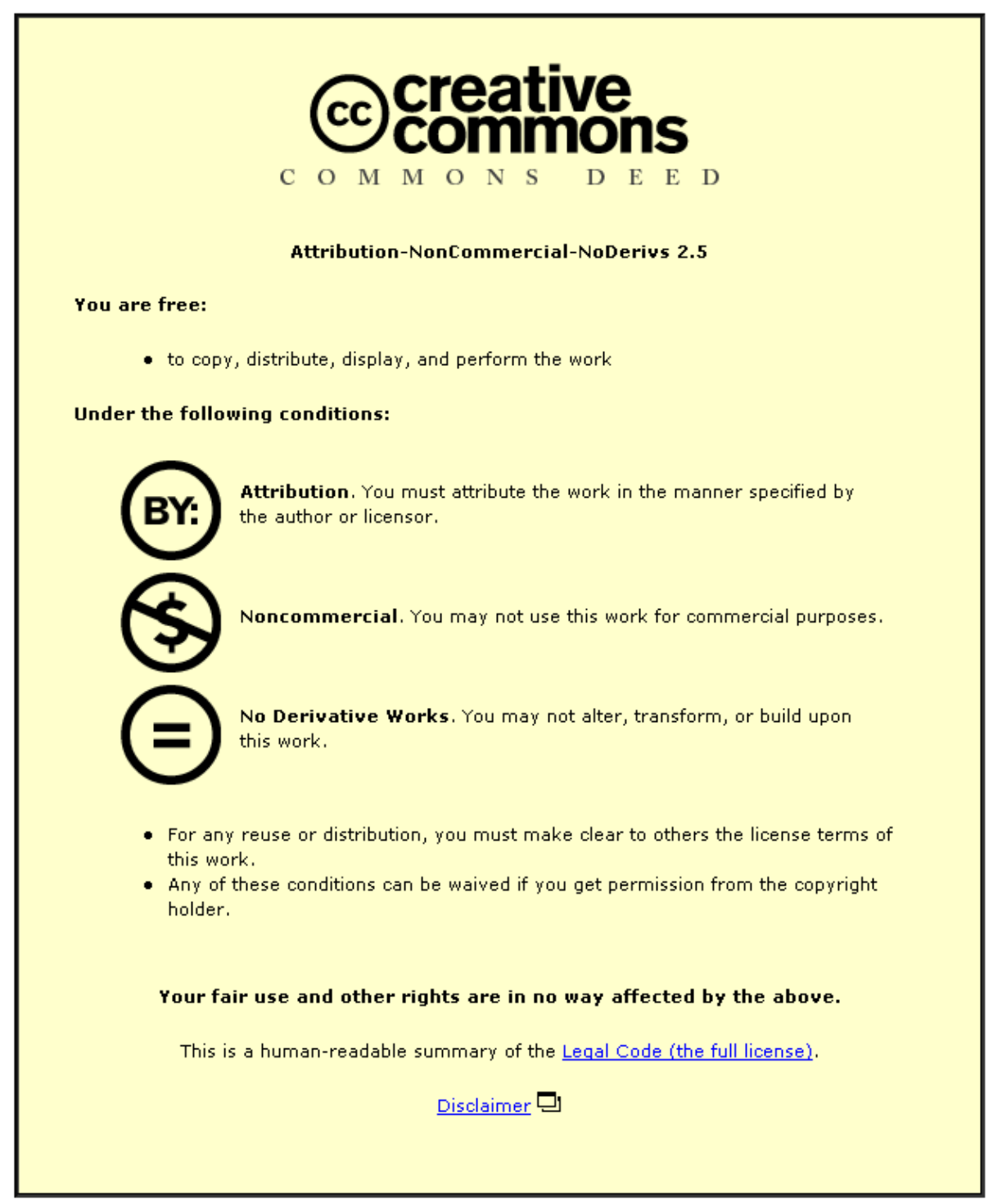

For the full text of this licence, please go to: http://creativecommons.org/licenses/by-nc-nd/2.5/ 
1 Physical education teachers' continuing professional development in

2 Health Related Exercise

3

4

\section{8}

Corresponding author:

Laura Ward

Building A

Monash University, Peninsula Campus

McMahons Road

Frankston

Victoria

3199

Australia

Email: laura.ward@monash.edu

Telephone: +61 (03) 99044421 


\section{Physical education teachers' continuing professional development in}

\section{Health Related Exercise}

Background: As a component of the physical education curriculum, Health Related Exercise (HRE) has been subject to intensive critique in terms of its status, organisation and expression in schools. Concerns and questions have also been raised about physical education teachers' professional knowledge of health and the extent to which HRE features within their continuing professional development (CPD) profiles.

Aims: This paper presents findings from a research project which investigated English secondary physical education teachers' experiences, views and understandings of HRE and related CPD (HRE-CPD). It also draws upon existing research, sociological theory and the concept of 'philosophies' in order to present an explanatory model which may help the physical education profession better understand the often problematic organisation and expression of HRE in schools.

Methods: The research was undertaken via a two-phase, mixed-method study. Phase one consisted of a survey questionnaire, which was completed by 112 secondary physical education teachers. Phase two involved semi-structured interviews with 12 teachers from the phase one sample.

Results and Discussion: The survey revealed that approximately half of the physical education teachers who participated in the study reported to have had no prior professional experience of HRE before teaching it, and most had not taken part in any CPD related to health and lifelong physical activity in the previous 12 months $(80 \%)$ or three years $(70 \%)$. Further, the teachers' responses to both the survey and the interviews suggest that HRE within physical education continues to be characterised by incoherence and misunderstanding. The interdependent and emerging themes which provided an explanation for this include: i) the tendency for the teachers' philosophies to bear the hallmark of sport and fitness related ideologies; ii) many of the teachers' narrow understandings of HRE and how best to teach it; iii) the teachers' largely misguided confidence in their ability to teach HRE; iv) a general lack of teacher engagement with any CPD related to health and lifelong physical activity.

Conclusions: With regard to HRE, both the 'I' in ITE and the ' $\mathrm{C}$ ' in CPD appear to have been overlooked, and this inevitably raises questions about the degree to which teachers are prepared to teach this area of the curriculum. It is argued that now is the time for action, and that relevant, effective and ongoing CPD has the capacity to address the problematic teaching of HRE and develop in teachers the knowledge, skills and understandings that are necessary to promote healthy, active lifestyles among young people. Many physical education teachers are not engaging in HRE-CPD but in order to disturb common and often narrow understandings of HRE it is arguably necessary What a conundrum!

Keywords: physical education; teachers; continuing professional development; health related exercise, sociology. 


\section{Summary for Practitioners}

2 This paper presents findings from a study that explored English secondary physical

3 education teachers' experiences, views and understandings of Health Related Exercise

4 (HRE) and related continuing professional development (HRE-CPD). The results

5 revealed that many of the teachers had not engaged professionally with HRE before

6 being expected to teach it. There was a tendency for the teachers to demonstrate

7 narrow understandings of HRE, with many seeming preoccupied with sport and

8 fitness. Given the pressures upon physical education teachers to promote healthy,

9 active lifestyles, their lack of HRE-CPD is an issue. This paper highlights the issue 10 and discusses some contributing factors, and a forthcoming paper draws on broader

11 findings from the same research project to suggest how it can be overcome.

\section{Introduction}

Over the past decade there has been increasing academic, political and media interest, on a global scale, in the role of schools and physical education in promoting healthy, active lifestyles. Indeed, there is a long-standing assumption that schools generally play a fundamental role in producing healthy nations (Penney and Jess, 2004; Salmon et al. 2007) and that physical education and Health Related Exercise (HRE) specifically are key vehicles through which to promote health and physical activity among young people (Harris, 2010; Kirk, 2006; Seghers, de Martelaer and Cardon, 2009; Stratton et al., 2008; Webb and Quennerstedt, 2010). In England, Australia, New Zealand, Canada and the United States, this assumption has consistently been manifested within various government policies, initiatives and documents (Bulger, Mohr, Carson and Wiegand, 2001; Cale, 2000; Evans et al. 2008; Gard and Wright, 2005; Penney, 2008; Wright \& Burrows, 2004). For example, 'Healthy Weight, Healthy Lives' (Department of Health and Department for Children, Schools and 
1 Families, 2008), 'Healthy Weight 2008: Australia's' Future' (Department of Health

2 and Aging, 2003) and the 'Physical Education for Progress Act' (U.S. Department of

3 Education, 2001) have all served to reinforce the view that schools, and physical

4 education in particular, have a responsibility to promote health and physical activity.

Public messages also continue to place schools and most notably physical

6 education in a prominent position with regards to the health of young people (Kirk,

7 2006; Rich, 2011). An article from an English newspaper (The Guardian), for

8 example, reported that a leading doctor "accused schools of making children more

9 overweight after government figures showed rates of obesity rise" (Batty, 2008). In

10 the same article "Dr David Haslam, Clinical Director of the National Obesity Forum

11 called for children to do more physical education" in order to combat the rise in 12 overweight children (Batty, 2008). These kinds of messages have, over time,

13 presented physical education as both a problem and a solution in terms of particular

14 public health issues such as obesity (Gard and Wright, 2005; Webb and Quennerstedt,

15 2010). Given claims that physical educators have a responsibility for public health

16 promotion, it is considered important to explore their experiences, views and

17 understandings of the most obvious vehicle through which physical activity and

18 health can be promoted within the curriculum, namely HRE.

19 HRE is known by a range of terms globally (such as Health Related Fitness

20 and Health Based Physical Education) and is a statutory component of physical

21 education curricula in England, Australia, New Zealand, Canada and the United States

22 and beyond. At the risk of over-simplifying, the purpose of HRE is to promote in

23 pupils the knowledge, skills and understanding necessary to lead healthy, active

24 lifestyles (Harris, 2010; Qualifications and Curriculum Authority, 2007). Within the

25 most recent National Curriculum for Physical Education (NCPE) in England, for 
1 example, HRE is concerned with the 'key concept' of 'healthy, active lifestyles'

2 (QCA, 2007, 191) and it seeks to promote the 'key process' of 'making informed

3 choices about healthy, active lifestyles' (QCA, 2007, 193). Essentially, HRE is a

4 context within which pupils should learn through active participation in purposeful

5 activity embracing a broad and balanced range of educative experiences (Cale and

6 Harris, 2009b).

Although HRE has been a statutory component of physical education curricula since the late 1980s and early 1990s, literature reveals continuing concerns over its

9 status, organisation and expression in schools (Almond and Harris, 1997; Harris, 10 1994, 2009; Trost, 2006). More recently, questions have also been raised about 11 physical education teachers' professional knowledge of health and the extent to which 12 they have engaged with continuing professional development in the area (HRE-CPD) 13 (Cale, Harris and Leggett, 2002; Trost, 2006; Ward, Cale and Webb, 2007). Armour 14 and Harris (2008) have suggested that the physical education profession seems 15 uncertain about its role in public health, unclear about the kinds of health knowledge 16 required, and the level of responsibility it is willing to accept for delivering health 17 outcomes.

The work of Leggett (2008) confirms concerns relating to the expression of 19 HRE and suggests that whilst rhetoric within the physical education domain tends to 20 focus on healthy, active lifestyles, HRE in practice often mitigates against this by 21 focusing upon the 'products' of sport performance and fitness. This issue is not new 22 and Harris $(1997,2010)$, amongst others, has continued to make this point for over a 23 decade. While sport performance and fitness are valuable components of physical 24 education, it is argued that an over emphasis upon these products as opposed to the 25 processes underpinning them can limit pupil learning and engagement. 
In terms of professional knowledge, the concerns surrounding physical

2 education teachers' HRE knowledge are not confined to England. Similar issues have

3 been identified in Australia (Brown, 2003) and North America (Castelli and Williams,

4 2007). Castelli and Williams (2007) carried out a study whereby they tested the

5 Health-Related Fitness ${ }^{1}$ (HRF) knowledge of 73 physical education teachers. Whilst

6 the findings revealed that the teachers were very confident in their perceived

7 knowledge of HRF, their test scores did not meet the standard of achievement

8 expected of a ninth-grade student. It was thus concluded that a large proportion of the

9 teachers did not have the necessary knowledge to teach pupils in, through and about

10 HRF and consequently CPD was highlighted as an issue of "the highest importance"

11 (Castelli and Williams, 2007, 14).

Over the past decade the concept of CPD has become increasingly valued, at

13 least at policy level (Keay, 2005, 2007a), and it has been suggested that CPD is "an

14 expectation of all professionals" (Day and Sachs, 2004, p.4) and "both a contractual

15 right and a contractual duty" for all teachers (Johnson, 2001, p.5). That is to say, if

16 teachers are to be 'professionals' then it is necessary for them to continually engage

17 with professional development. The increasing value attached to CPD has been

18 evidenced by extensive government investment in England through the National CPD

19 Strategy (Department for Education and Employment [DfEE], 2001) and the

20 Department of Education's 'National Strategies' (2008) which seek to raise standards

21 of teaching and learning by encouraging teachers to maximise their CPD

22 opportunities (Day et al., 2006; Keay, 2005). It has been argued that the heightened

23 interest in teacher CPD is associated with the growing acknowledgement of its effect

\footnotetext{
1 Health-related fitness is another term for HRE and one that is commonly used in North America. (HRF is also used by some in the UK).
} 
1 upon pupil learning (Armour and Yelling, 2007; Borko, 2004; DfEE, 2001, Guskey

2 and Sparks, 2004). Whilst teacher CPD should not be viewed as a panacea for all that

3 is wrong with education (Armour and Yelling, 2007; Fishman, Marx, Best and Tal,

4 2003), research suggests that it can contribute in a positive way towards the quality of

5 teaching and learning in schools (Armour and Yelling, 2007). With regard to HRE in

6 particular, and as noted earlier, questions have been raised over physical education

7 teachers' knowledge of the area, and the extent to which it features within their CPD

8 profiles (Almond and Harris, 1997; Armour and Harris, 2008; Armour and Yelling,

9 2004; Cale, Harris and Leggett, 2002; Castelli and Williams, 2007).

10 Acknowledging that ITE is, of course, also a crucial part of the teacher CPD

11 process, it is therefore concerning that the structure and funding of ITE in England often

12 serves to "limit prospective teachers' experiences of Health-Related Exercise within the

13 curriculum" (Harris, 2005, p.91). Similarly, in North America there is evidence to suggest

14 that ITE "may inadequately address the needs of prospective physical educators in the

15 areas of physical activity promotion and health-related physical fitness" (Bulger et al.,

16 2001, p.404).

17 While physical education teachers' experiences of HRE-CPD have been raised

18 as a matter of concern, the reasons underpinning these remain relatively unexplored.

19 In light of the issues identified above and the relative gap in the literature, this paper

20 presents and discusses findings from a research project which explored English

21 secondary physical education teachers' experiences, views and understandings of

22 HRE and HRE-CPD. The concepts of 'philosophies'2 (Armour and Jones, 1998;

\footnotetext{
2 Teachers' philosophies are grounded in their context, and comprise an array of beliefs and underlying ideologies that result from "personal and sporting biographies and...working context" (Green, 2003, p.146).
} 
1 Evans, 1992; Green, 2003) and 'residual ideologies'3 (Kirk, 1988) are drawn upon in

2 order to illuminate the role of prior knowledge and experience in teachers' knowledge

3 construction as it relates to HRE (Kirk, 1988). Finally, a model is presented in order

4 to explain the relationships between some of the concepts and themes which emerged

5 from the study.

\section{The Research Process}

7 The objectives of inquiry were addressed via two phases of research. Phase one

8 involved a survey questionnaire completed with a sample of physical education

9 teachers from secondary schools across England. Phase two comprised semi-

10 structured interviews with a sample of twelve teachers drawn from the original

11 broader sample. From a figurational sociological perspective, if one is to understand a

12 particular social phenomenon it is imperative to trace its socio-historical development.

13 On this basis it was important not to address the teaching of HRE as an issue in time

14 but, rather, to attempt to trace the teachers' experiences, views and understandings

15 over time (i.e. from their own school experiences, to their experiences of ITE, to their

16 current experiences and views of HRE and their CPD).

Acknowledging that teachers do not exist in a vacuum, a process or

18 'figurational' sociological approach (Elias, 1978, 2000) allowed for an appreciation of

19 the complex and dynamic web of human interdependencies within which the teachers

20 were enmeshed (van Krieken, 1998). As part of a socio-historical frame, characteristic

21 of a figurational approach (Mennell, 1992), the central concept of 'figuration' was

22 used to illuminate the network of interdependent relationships (figurations) which

23 served to both enable and constrain the physical education teachers' engagement with

\footnotetext{
3 The term 'residual ideologies' refers to the influence of prior knowledge and experiences upon
} physical education teachers' orientation and practices. 
1 HRE and HRE- CPD. The concept of figuration encouraged a consideration of the

2 ways in which the teachers were enabled and constrained in certain ways as a result of

3 ever-changing, multi-directional relationships with others (Green, 2003; Mennell,

4 1992). For example, teachers' day-to-day practices can be influenced by the pupils

5 they teach, their past and present colleagues and policy makers.

\section{Phase One}

A total of 112 teachers agreed to participate in the study. They were selected

8 from a proportionate, stratified random sample of schools from Local Authorities

9 (LAs) across England. The Schools' Web Directory (www.schoolswebdirectory. co.uk) for England identified 148 LAs and each was categorised according to size ${ }^{4}$

11 small, medium, large - and a proportionate number of schools were selected from each category. Based on these categories, there were two small, 121 medium and 24

13 large LAs. Two schools were selected from each small LA, three schools from each 14 medium LA, and four from each large LA. Within each LA, schools were listed in 15 alphabetical order and, where possible, every tenth school was selected. With LAs with less than 10 schools, every fifth school was chosen. The majority (90\%) were

17 state schools, $13 \%$ of which were Specialist Sports Colleges ${ }^{5}$, and the remainder were 18 independent or academies. Having selected the schools, questionnaires were sent to 19 the Head of Department (HoD) for physical education within each. Accompanying the 20 questionnaire was a self-addressed envelope and a covering letter requesting 21 permission for a physical education teacher within the department to take part in the

\footnotetext{
${ }^{4}$ Small (comprising 2-5 secondary schools), medium (6-49 secondary schools) and large (more than 49 secondary schools).

5 Specialist Sports Colleges are part of a broader government initiative, 'Specialist schools', which position PE and sport at the centre of the curriculum, using it as a vehicle to develop and improve learning opportunities for all.
} 
1 study. More specifically, and in order to reduce the risk of 'sampling error', male and

2 female physical education teachers representing different levels of teaching

3 experience were included within the sample (Day et al., 2006) by asking each HoD to

4 ensure that a teacher of a particular sex and experience completed the questionnaire.

5 Experience categories comprised of: i) 0-7 years; ii) 8-15 years; and iii) 16 plus years

6 of experience, organised around the 'Professional Life Phases' proposed by Day and

7 colleagues (2006). Emphasising the difference between professional life phases

8 highlights the processual nature of teaching and furthermore acknowledges that

9 teachers are dynamic, continually changing and far from homogenous (Elias, 1978;

10 Green, 2008; van Krieken, 1998).

11 The survey questionnaire was developed to explore the physical education 12 teachers' experiences, views and understandings of HRE and HRE-CPD. Their 13 engagement with physical education CPD (PE-CPD) more generally was also 14 investigated in order to provide a benchmark for comparison. From a figurational 15 perspective, social phenomena are determined by socio-historical processes and are 16 directed towards future events (van Krieken, 1998). When designing the 17 questionnaire, therefore, it was considered important to avoid being present-centred 18 (Elias, 1987) but to look at the teachers' engagement with HRE and HRE-CPD over 19 time.

The survey comprised four sections which focused on: i) demographics; and 21 the teachers' experiences, views and understandings of ii) HRE; iii) PE-CPD; and iv) 22 HRE-CPD. With reference to Tsangaridou's (2006, p.487) 'categories of experience', 23 and in order to explore engagement over time, particular attention was paid to the 24 teachers' HRE and HRE-CPD experiences, as applicable: i) at school as a pupil; ii) 25 during their ITE; iii) whilst teaching; and vi) within their general life experiences. The 
1 questionnaires were coded for follow-up purposes. Quantitative data from the

2 questionnaires were entered into SPSS 16.0 (Statistical Package for the Social

3 Sciences) for analysis and descriptive statistics were employed. Responses to

4 qualitative questions were transcribed verbatim and coded using NVivo 8 software.

5 The use of this software is explained in the following section.

6 Phase Two

7 A purposive sample of twelve teachers ${ }^{6}$ (six male and six female) was drawn from the

8 phase one sample. In selecting the teachers, the intention was to obtain a group that

9 included males and females from different types of schools within different LAs.

10 Attention in selection was also paid to the teachers' reported experiences of HRE, PE-

11 CPD and HRE-CPD, with those chosen having varying amounts of each. The

12 interviews provided an opportunity to expand upon, clarify and add meaning to the

13 questionnaire findings. Whilst each interview schedule was slightly different, all were

14 organised into five sections and, as with the survey, focused broadly on the teachers'

15 experiences, views and understandings of HRE, PE-CPD and HRE-CPD. Interviews

16 took place in a quiet room, were recorded with permission from the interviewees, and

17 lasted between 50-90 minutes. Following the interviews, the transcripts were prepared

18 and electronically mailed to each teacher for them to check for accuracy.

19 The transcripts were coded using NVivo 8 software. This allowed for the

20 generation and organisation of ideas, and the gathering of data by topic or 'node'

21 (Silverman, 2006). Examples of the nodes which emerged included

22 'professionalisation', 'sport' and 'fitness'. In analysing the data, the work of Elias

23 (1978) and, in particular, the concept of 'figuration' proved useful. As highlighted

\footnotetext{
6 The decision to interview 12 teachers was informed by the literature including a review of 22 studies involving teachers which revealed an average sample size of 12 (Beijaard, Meijer and Verloop, 2004).
} 
1 earlier, locating the teachers within their historically-rooted figuration encouraged an

2 appreciation of the social interdependencies (e.g. with their Head of Department) and

3 processes (e.g. the privileging of sport within physical education) which had come to

4 both enable and constrain their experiences of HRE and HRE-CPD over time.

\section{Physical Education teachers' experiences of HRE over time}

6 The findings revealed that less than half $(43 \%)$ of the teachers reported to have been 7 taught HRE whilst they were at school. Of those who had, many (63\%) had had a 8 positive experience of the area. Most of the teachers were taught about HRE as pupils, 9 mainly through cross-country running (59\%) and circuit training (38\%). Focusing upon 10 ITE, approximately half (49\%) of the teachers had engaged with HRE but approximately 11 three quarters of the sample felt that that the amount (76\%), content (74\%) and structure $12(73 \%)$ of their HRE-ITE, as well as the support (79\%) they received was inadequate. 13 Over half also felt that their ITE had failed to prepare them to teach PE generally (58\%) 14 and HRE specifically (73\%). That said, most of the teachers reported to be 'confident' or 15 'very confident' in teaching HRE (86\%) and viewed it as a 'valuable' or 'extremely 16 valuable' aspect of Physical Education (96\%).

Overall, the survey revealed that only half of the physical education teachers 18 reported to have had prior experience of HRE (either at school or during their ITE)

19 before being expected to teach it. Furthermore, only a minority had taken part in any 20 related CPD in the previous 12 months (20\%) or three years (30\%) (see Figure 1).

\section{INSERT TABLE 1}

These findings confirm concerns highlighted in previous research which suggest that

23 health and lifelong physical activity are two areas which tend to be absent from 24 teachers' CPD profiles (Armour and Yelling, 2004; Castelli and Williams, 2007; 25 Harris, 2010; Kulinna, McCaughtry, Martin, Cothran and Faust, 2008; Trost, 2006). 
1 The findings also raise questions about the extent to which the physical education teachers in the study were equipped to teach pupils about health and lifelong physical

3 activity. interviews, with many of the teachers reinforcing how their professional development had not adequately prepared them to teach HRE:

31 These quotations support previous work which discusses the importance of ITE,

I've never been on a course for HRE... I guess that it's (HRE-CPD) just never been made readily available. (Nathan, male, 4-7 years of experience)

In terms of HRE I wouldn't say I've really learnt how to teach it. (Toni, female, 8-15 years of experience)

There hasn't been CPD to do with HRE. (Ethan, male, 8-15 years of experience)

As stated earlier, teachers are enabled and constrained in certain ways as a result of ever-changing, multi-directional relationships with others. During their ITE, for example, pre-service teachers' engagement with HRE is very much constrained by often time-poor teacher educators. As just noted, almost three-quarters $(73 \%)$ of the teachers felt they had not been adequately prepared to teach HRE during their ITE. The quotations below are representative of most of the teachers who were interviewed.

It would have been valuable to have had some insight into HRE (during ITE)... I had to work my ass off to build my resources and knowledge around it. (Sophie, female, 0-3 years of experience)

Regarding HRE, my ITE was pretty much bog standard. I definitely would have wanted more training on the course and info on delivery. (Stuart, male, 4-7 years of experience)

whilst also acknowledging that it may not be adequately preparing prospective 
1 physical educators to meet their professional responsibilities related to HRE (Bulger

2 et al., 2001; Fox and Harris, 2003).

While many of the teachers had not engaged with HRE-CPD, most (87\%) had

4 participated in some form of professional development in the previous 12 months and

5 the majority reported positive experiences. These findings thus highlight the disparity

6 between the teachers' engagement with professional development generally and 7 health related CPD specifically. As highlighted earlier, given the on-going concerns

8 surrounding the teaching of HRE, together with the responsibility placed on physical

9 education teachers to promote healthy, active lifestyles, the lack of teacher 10 engagement in health related CPD is an issue.

11 Opportunities for HRE-CPD do exist in England (for example, HRE modules 12 were offered as part of the National CPD Strategy [DfEE, 2001]) but the earlier 13 quotations from Nathan and Ethan suggest that a limited awareness of these is an 14 issue. Given the teachers' general lack of awareness of the HRE-CPD available, it is 15 not surprising that many of the teachers had not experienced any. Clearly, if teachers 16 are not aware of opportunities to engage in HRE-CPD they will not access them, 17 regardless of whether they recognise the need to do so. This issue needs addressing 18 sooner rather than later.

19 For the minority of teachers who had experienced HRE-CPD, both the survey 20 and interview data suggested that their experiences had typically focused upon fitness 21 testing, circuit training and how to use fitness equipment. For example, during the 22 interview one teacher stated "We recently just did fitness testing which was run by the 23 Head of Department and the year coordinator" (Ethan, male, 8-15 years of 24 experience). While this experience may have been useful in some respects, it does not 
1 reflect the broad and multi-dimensional nature of HRE and is likely to do little to

2 further enhance or develop teachers' experiences and understandings of the area.

With regards to the teaching of HRE, in a third of the schools (33\%) the

4 physical education teachers did not have access to unit or lesson plans or resources to

5 support their practice. As Harris (1997) noted following similar findings from her

6 study, a lack of planning and resources raises questions about structure, progression

7 and coherence within HRE. Moreover, their absence in some schools could be taken to reflect a generally 'ad-hoc' attitude towards HRE and perhaps teaching more

9 broadly, as evidenced by comments from some of the teachers interviewed:

It's an easy lesson to deliver more to the point... ad hoc. (Toni, female, 8-15 years of experience)

We don't have a unit on health-related issues unless they [the pupils] opt for GCSE PE. A health-related strand runs through all units but the topic is not set in stone. We don't have a scheme of work. (Joanne, female, 4-7 years of experience)

While planned and well-resourced HRE (or physical education more generally) does not necessarily equate to a progressive, coherent and educationally sound programme, it would seem to be one way of maximising this possibility.

The NCPE in England outlines the content to be taught within physical education but does not stipulate how it should or could be taught. Given this flexibility, it seems the majority of the teachers in this study chose to teach HRE predominantly though fitness related activities (usually fitness testing and circuit training), with links often being made to sports performance. For example:

Implicit in all lessons, all physical education lessons is the fitness element... it's gotta run through all the activities that you run, they've gotta have that fitness element, it has to be there. (Philip, male, 30+ years of experience)

Fitness is prioritised... HRE is obviously to do with how fit we are. (Fred, male, 8-15 years of experience) 
For rugby and football we try and do a number of fun tests with the kids based around the bleep test and we incorporate tackle bags, kicking skills and things like that so we try and make it a bit more specific to sport ... and basketball skills into circuit training, so instead of just doing weights and press ups and sit ups, they are doing skills of a certain game so they are learning skills and doing repetitions of skills instead of repetitions of press ups. (Nathan, male, 4-7 years of experience)

The fitness orientated approach to HRE reflected in these quotes is not a new phenomenon (Capel, 2007; Green, 2008; Leggett et al., 2008; Penney, 1998). Indeed,

the findings suggest that little has changed since the earlier work of Harris (1994;

1997) which revealed that physical education teachers often focused upon fitness rather than the broader concept of health.

While the findings paint a relatively bleak picture for HRE, it is important to highlight that there were also some positive findings from the research. For example, one teacher, Sophie (female, 0-3 years of experience), was an anomaly with regards to her experiences, views and understandings of HRE. During the interview with Sophie it was clear that, in comparison to the other teachers, her philosophies and practices were not as heavily circumscribed by residual sport and fitness related ideologies ${ }^{7}$.

Rather, she was found to have a broader HRE biography 8 , and 'physical activity for health' featured more heavily within her philosophies. After competing in gymnastics at regional level, Sophie suggested that her interest in HRE was:

mostly down to working in the gym at university. After my boss forced me to deliver classes, I learned I actually loved it and so I brought that into school with Fit ball and Boxercise lessons. I also enjoy doing the Pump It Up DVDs 'n' stuff like that at home so I like challenging the kids with the routines I pick up. (Sophie, female, 0-3 years of experience)

\footnotetext{
7 Although sport and fitness ideologies are discussed together, they are indeed separate but often related.

8 The term 'HRE biography' refers to the teachers' views and experiences of HRE across their life span.
} 
1 From the above it is interesting to note that the experiences which Sophie valued and

2 which had prepared her most to teach HRE tended to be from general 'life

3 experiences' (O'Sullivan, 2005; Tsangaridou, 2006) as opposed to experiences gained

4 at school, during her ITE or whilst teaching. Similarly, another teacher stated during

5 his interview that "A lot of my HRE knowledge comes from personal interest -

6 magazines, websites and DVDs" (Stuart, male, 16-30 years of experience).

Although popular media can provide useful information it may not always be wholly accurate, reliable and appropriate for an educational context. In our view, the resources physical education teachers primarily draw upon to inform their teaching of

HRE should be specific to the area and in keeping with National (or State) Curriculum

11 requirements. As revealed earlier, the teachers were rarely aware of CPD opportunities and resources that could support and guide their teaching of HRE.

13 Consequently, some may have felt it necessary to acquire HRE knowledge through 14 more 'popular' or 'public' means. This trend has been discussed in broader terms by 15 Giroux (2004) and more recently Rich (2011), who argue that learning and 'public 16 pedagogies' related to health occur in and through "sports and entertainment media, cable television networks, [and] churches..." (Giroux, 2003, 497), as well as in schools and universities. With this in mind, the perhaps limiting influence of popular pedagogies upon physical education teachers' (and therefore pupils') knowledge and understandings of health and HRE should not be underestimated.

The limitations of teachers uncritically drawing upon popular pedagogies are

22 further heightened when we consider the numerous developments within education in 23 recent years which are of relevance to HRE (such as curriculum revisions, new 24 physical activity recommendations for young people, and the introduction of 25 government initiatives such as 'Healthy Schools'). If physical education teachers are 
1 to be effective, then it would seem important that they are kept abreast of such

2 developments via accessing appropriate resources and CPD opportunities. The

3 findings from the present study, however, suggest that this is not happening in all

4 schools.

$5 \quad$ Health Related Exercise: What a conundrum!

6 The previous section highlighted physical education teachers' experiences of HRE

7 over time and revealed a number of issues associated with these. Drawing upon these

8 findings, previous research and the concept of 'philosophies', this section presents a

9 model (see Figure 1), referred to as 'The HRE Conundrum', in an attempt to explain

10 these issues and better understand the often-problematic organisation and expression

11 of HRE in schools. The model comprises four stages, each of which is discussed in 12 turn.

\section{INSERT FIGURE 1}

\section{Physical education teachers'philosophies: The privileging of sport and fitness}

The tendency for the teachers to focus upon sport and fitness within HRE was arguably a manifestation of their deeply-rooted and often persistent 'philosophies' which, for the most part, were strongly attached to sport and fitness ideologies (e.g. sports participation equates to health). This claim supports that of Kirk (1988) and Green (2003) who proposed that residual sport and fitness ideologies permeate many physical education teachers' philosophies, with their past experiences of physical education and sport leading them to privilege the latter. As a result, teachers generally tend to apply a sporting frame when teaching other components of physical education, including HRE. While the presence of sport and fitness ideologies within physical education is not necessarily negative, an over emphasis upon them at the 
1 expense of a broad and balanced curriculum may limit pupil learning in this context.

2 Further, given that a large proportion of the teachers had not engaged with HRE-CPD

3 in the three years prior to the research, there will have been limited opportunities for

4 their philosophies to be meaningfully challenged or changed in any way.

\section{Narrow understandings of HRE: The manifestation of privileged ideologies}

Findings from both phases of the study suggested that the majority of the teachers held narrow, inconsistent and at times contradictory views with regards to the aims of HRE. For example, when asked what they viewed the aims of HRE to be, one teacher reported that it "is to improve fitness levels" (Sarah, female, 4-7 years of experience), whilst another claimed "HRE is a massive way of keeping people within sport" (Nathan, male, 4-7 years of experience). Not only do these quotations reflect a narrow understanding of HRE but also a privileging of sport and fitness in this context.

Traditionally the terms 'fitness' and 'health' have been confounded (Waddington, Malcolm and Green, 1997) and, as such, it is perhaps not surprising that some of the teachers tended to use one term, usually 'fitness', to refer to both concepts. It is suggested that the ideologies and core assumptions that seem to have infiltrated physical education teachers' philosophies (Capel, 2007; Green, 2003) have constrained their understandings and the development of HRE and reduced the focus to the 'product' of physical fitness as opposed to the 'process' of lifelong physical activity and health. This reductionist approach was also evidenced by the narrow range of teaching methods which the teachers appeared to adopt. Previous research has likewise acknowledged this as an issue (Harris, 1997; Leggett, 2008).

As mentioned earlier, both the survey and the interview data suggested that fitness testing and circuit training were the most popular vehicles through which to 
1 teach HRE. Yet, Cale and Harris (2009b, 103) suggest that fitness testing in schools

2 "may well represent a misdirected effort in the promotion of healthy lifestyles and

3 physical activity, and that physical education time could therefore be better spent".

4 Similarly, Garrett and Wrench $(2008,21)$ contend that "the continuing and

5 unproblematic use of fitness testing in schools and universities might actually

6 contribute to narrow learning outcomes that cause more pain than pleasure". It is

7 maintained, however, that if carried out appropriately, in an individualised and

8 educational manner as part of a planned HRE programme, fitness testing could be

9 valuable in terms of promoting physical activity (Cale and Harris 2009b; Cale et al., 10 2007).

11 Physical education teachers and HRE: Misguided value and confidence

12 How physical education teachers express HRE is likely to be influenced by

13 how they view and understand the area. The survey findings suggested that most of 14 the teachers valued HRE (96\%) and were confident in their ability to teach it $(86 \%)$.

15 The subsequent interviews provided an opportunity for teachers to communicate the reasons underpinning the value they attached to HRE, with one teacher stating:

If physical education was a wheel, HRE would be the hub. Although it's the smallest bit, without that everything falls apart... Understanding as well, we really need to push that. Later on, you hope that they will continue to do activities 'cause they enjoy it, but also for the benefits for their body. (Philip, male, $30+$ years of experience)

Whilst it is perhaps encouraging that most of the physical education teachers

23 in this study valued HRE and felt confident teaching it, according to Cale $(2000,167)$,

24 if teachers are to be successful in promoting healthy, active lifestyles amongst young

25 people it requires "more than an enthusiasm for and belief in its value, importance and role". Indeed, if the aims of HRE are to be achieved, teachers need to have a clear 
1 understanding of the area, and of the distinction between the terms health, fitness,

2 physical activity and sport. The findings suggest, however, that this was not the case.

In terms of the teachers' confidence, these findings support those of Castelli

4 and Williams (2007), reported earlier, in that while the teachers claimed to be

5 confident in their ability to teach HRE, their experiences and understandings of the

6 area were often limited. Given that approximately half of the teachers had not

7 formally experienced HRE in any capacity prior to being expected to teach it, it is surprising that the majority felt so confident.

It is proposed that the teachers' misguided value and confidence were rooted, at least in part, in their philosophies and narrow understandings of HRE. It appears

11 that the teachers felt confident in their ability to promote knowledge, skills and understanding through sport and fitness related activities (such as fitness testing and circuit training), but were less aware of other means by which they could do this. For example, when asked if he felt confident teaching HRE in comparison to other areas of physical education, Thomas (male, 0-3 years of experience) stated,

Yeah, I'm quite a confident teacher through my own sport. When I was playing sport as a participant, a lot of the things we did were related to HRE, fitness testing ' $n$ ' stuff, so I've had experience of doing it myself.

Despite Thomas's claims of confidence, by focusing upon sport and fitness within his response he highlighted the privileged ideologies within his philosophies, as well as his narrow understanding of the nature and purpose of HRE. While sport may be one valuable vehicle through which to deliver HRE, an over-emphasis on it at the expense of other broader educational experiences is considered limiting.

\section{HRE and the status quo}

26 The preceding discussion has confirmed that the historically rooted concerns surrounding the organisation and expression of HRE continue to be evidenced and 
1 reinforced across multiple levels and over time. Further, the present findings suggest

2 that some of the contributing factors (such as the nature of teachers' philosophies) to

3 these concerns are not being addressed. If these findings are representative of physical

4 education teachers generally, as other literature suggests they are likely to be, then

5 this is an issue which needs to be addressed. With reference to the HRE conundrum

6 introduced earlier (figure 1), it would seem that physical education teachers'

7 philosophies and practices, often bearing the hallmark of sport and fitness ideologies,

8 need to be challenged via relevant, effective and ongoing HRE-CPD. In the absence

9 of sufficient challenge, status quo prevails and HRE will continue to be characterised

10 by incoherence, misunderstanding and an overriding focus on sport and fitness related

11 knowledge and practice.

12 Whilst it has been acknowledged that this issue is not confined to England, the

13 findings presented in this paper originate from the English context and the authors are

14 therefore not in a position to comment on their transferability to other countries or

15 contexts. That said, some of the findings may be generalisable in similar curriculum

16 contexts where HRE (or the equivalent) is a recognised component. It is argued that now is the time for action, and that relevant, effective and ongoing CPD has the capacity to address the problematic teaching of HRE and develop in teachers the

19 knowledge, skills and understandings that are necessary to promote healthy active 20 lifestyles among young people. Potentially, CPD has an important role to play in 21 challenging the status quo and in equipping teachers with the knowledge, skills and 22 understandings they need to effectively teach HRE. The process of CPD is especially 23 pertinent when the growing acknowledgement of its effect upon pupil learning is 24 recognised (Armour and Yelling, 2007; Borko, 2004; DfEE, 2001, Guskey and 25 Sparks, 2004). Yet, given the misguided confidence physical education teachers seem 
1 to have in relation to HRE, encouraging them to participate in any related CPD

2 remains a challenge. Indeed, it appears that, with regards to HRE, both the 'I' in ITE

3 and the ' $\mathrm{C}$ ' in CPD have been overlooked and this inevitably raises questions about

4 the degree to which teachers are prepared to teach this area of the curriculum. If

5 physical education teachers' experiences, views and understandings of HRE are to be

6 broadened, this persisting cycle needs to be disturbed. It seems ironic however, that in

7 order to disturb common and often narrow understandings of HRE, HRE-CPD is

8 arguably necessary. What a conundrum!

\section{References}

11 Almond, L. and Harris, J. (1997) Does Health-Related Exercise Deserve a Hammering or a Help? British Journal of Physical Education, 28(2), 25-27.

Armour, K.M. and Harris, J. (2008) Great Expectations...and Much Ado About Nothing? Physical Education and Its Role in Public Health in England. Paper presented at the American Educational Research Association (AERA) Annual Conference, New York, North America, March 2009.

Armour, K. M. and Jones, R. (1998) Physical Education Teachers' Lives and Careers. PE, Sport and Educational Status. London: Falmer Press.

Armour, K. M. and Yelling, M. (2004) Continuing Professional Development for Experienced Physical Education Teachers: Towards Effective Provision. Sport, Education and Society, 9(1), 95-114. 
1 Association for Physical Education (afPE) (2008) Health Position Paper. Retrieved

2

3

4

5

6

7

10 October 2, 2008 from http://www.afpe.org.uk/public/downloads/Health_Paper Sept08.pdf

Batty, D. (2008) Retrieved on August 9, 2008, from http://www.guardian.co.uk/ society/2008/feb/21/health.health

Beijaard, D., Meijer, C. and Verloop, N. (2004) Reconsidering Research on Teachers' Professional Identity. Teaching and Teacher Education, 20, 107-128.

Borko, H. (2004) Professional Development and Teacher Learning: Mapping the Terrain. Educational Researcher, 33(8), 3-15.

Brown, T.D. (2003) The Development, Validation and Evaluation of the Physical Activity and Fitness Teacher Questionnaire (PAFTQ). Unpublished Doctoral Thesis, RMIT University.

Bulger, S.M., Mohr, D.J., Carson, L.M. and Wiegand, R.L. (2001) Infusing HealthRelated Fitness in Physical Education Teacher Education. Quest, 53, 403-417.

Cale, L. (2000) Physical Activity Promotion in Schools - PE Teachers' Views. European Journal of Physical Education, 5, 158-168. 
1 Cale, L. and Harris, J.(2009a) Fitness Testing in Physical Education - A Misdirected

Cale, L. and Harris, J.(2009b) Getting the Buggers Fit: The Complete Guide to Physical Education (London, Continuum).

Cale, L. Harris, J. and Chen, M.H. (2007) More Than 10 Years After 'The Horse is Dead . . .': Surely It Must Be Time to 'Dismount'?!, Pediatric Exercise Science, 19, 115-131.

Cale, L., Harris, J. and Leggett, G. (2002) Making a Difference? Lessons Learnt from a Health-Related Exercise Resource. Bulletin of Physical Education, 38(3), 145-160.

Capel, S. (2007) Moving Beyond Physical Education Subject Knowledge to Develop Knowledgeable Teachers of The Subject. The Curriculum Journal, 18(4), 493507.

Cardon, G. and De Bourdeaudhuij, I. (2002) Physical Education and Physical Activity in Elementary Schools in Flanders. European Journal of Physical Education, 7(1), 5-18. 
1 Castelli, D. and Williams, L. (2007) Health-Related Fitness and Physical Education

\section{.} Teachers' Content Knowledge. Journal of Teaching in Physical Education, 26,

Day, C., Stobart, G., Sammons, , Kington, A., Gu, Q., Smees, R. and Mujtaba, T. (2006) Variations in Teachers' Work, Lives and Effectiveness (Nottingham, DfES).

Department of Education (2008) The National Strategies. Accessed on August $12^{\text {th }}$ 2010 from http://nationalstrategies.standards.dcsf.gov.uk/cpd

Department for Education and Employment (2001) Learning and Teaching: A Strategy for Professional Development (London, HMSO).

Department of Health (2010) On the state of public health: Annual report of the Chief Medical Officer 2009 (London, HMSO).

Department of Health and Department for Children, Schools and Families (2008) Healthy Weight, Healthy Lives: A Cross-Government Strategy for England (London, HMSO).

Department of Health and Aging (2003) Healthy Weight 2008: Australia’s Future (Canberra, Commonwealth of Australia).

Elias, N. (1978) What Is Sociology? (New York, Columbia University Press). 
2 Evans, J. (1992) A Short Paper About People, Power and Educational Reform. Authority and Representation in Ethnographic Research. Subjectivity, Ideology and Educational Reform: The Case of Physical Education. In A.C Sparkes (ed.) Research in Physical Education and Sport: Exploring Alternative Visions (pp.1137). London: Falmer Press.

Evans, J., Rich, E., Davies, B. and Allwood, R. (2008) Education, Disordered Eating and Obesity Discourse: Fat Fabrications (London, Routledge).

Gard, M. and Wright, J. (2005) The Obesity Epidemic: Science, Morality and Ideology (London, Routledge).

Garrett, R. and Wrench, A. (2008) Fitness Testing: The Pleasure and Pain of It. ACHPER Healthy Lifestyles Journal, 55(4), 17-22.

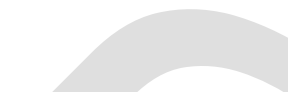

Giroux, H. (2004) Public Pedagogy and the Politics of Neo-Liberalism: Making the Political more Pedagogical. Policy Futures in Education, 2, 3-4, 494-503.

Green, K. (2003) Physical Education Teachers on Physical Education : A Sociological Study of Philosophies and Ideologies (Chester, Chester Academic Press).

Green, K. (2008) Understanding Physical Education (London, Sage). 
1 Guskey, T.R. and Sparks, D. (2004) Linking Professional Development to Improvement in Student Learning. In E.M.Guyton and J.R. Dangel (2004) (ed.) Research Linking Teacher Preparation and Student Performance (pp.11-22) Lanham: Scarecrow Education.

Harris, J. (1994) Health-Related Exercise in the National Curriculum: Results of a Pilot Study in Secondary Schools. The British Journal of Physical Education, 25(1), 15-19.

Harris, J. (1997) Physical Education : A Picture of Health? The Implementation of Health-Related Exercise in the National Curriculum in Secondary Schools in England. Unpublished Doctoral thesis, Loughborough University.

Harris, J. (2000) Health-Related Exercise in the National Curriculum at Key Stages 14. Guidance Material (Leeds, Human Kinetics).

Harris, J. (2010). Health-Related Physical Education. In R. Bailey (ed.), Physical Education for Learning: A Guide for Secondary Schools (London, Continuum).

Keay, J. (2005) Developing the Physical Education Profession: New Teachers Learning Within a Subject-Based Community. Physical Education and Sport Pedagogy, 10(2), 139-157.

Kirk, D. (1988). Ideology and school-centred innovation: A case study and a critique. Journal of Curriculum Studies, 20, 449-464. 
2 Kirk, D. (2006) The 'obesity crisis' and school physical education. Sport, Education and Society, 11(2), 121-133.

Penney, D. (1998) Positioning and Defining Physical Education, Sport and Health in the Curriculum. European Physical Education Review, 4(2), 117-126.

Penney, D. (2008) Playing a Political Game and Playing for Position: Policy and Curriculum Development in Health and Physical Education. European Physical 
1 Penney, D. and Jess, M. (2004) Physical Education and Physically Active Lives: A Lifelong Approach to Curriculum Development. Sport, Education and Society, 9, 2, 269-287.

Qualifications and Curriculum Authority (2007) The National Curriculum for England. London: HMSO. 2007

Rich, E. (2011) 'I see her being obesed': Public pedagogy, reality media and the obesity crisis. Health, 15, 1, 3-21.

Salmon, J., Booth, M.L., Phongsavan, P., Murphy, N. and Timperlo, A. (2007). Promoting Physical Activity Participation among Children and Adolescents. Epidemiological Reviews, 29, 144-159.

Seghers, J. de Martelaer, K. and Cardon, G. (2009) Young people's health as a challenge for physical education in schools in the twenty-first century: the case of Flanders (Belgium) Physical Education and Sport Pedagogy, 14: 4, 407420.

Silverman, D. (2006). Interpreting Qualitative Data (3rd ed.) (London, Sage).

Stratton, G., Fairclough, S. and Ridgers, N. (2008) Physical Activity Levels during the School Day. In A.L.Smith and S. J.H. Biddle (2008) (ed.) Youth Physical Activity and Sedentary Behaviour. Challenges and Solutions (p321-350) (Leeds, Human Kinetics). 
1 Tsangaridou, N. (2006) Teachers' beliefs. In D. Kirk, D. Macdonald, and M.

O’Sullivan (ed.) The Handbook of Physical Education (p486-501) (London, Sage).

Trost, S. (2006) Public Health and Physical Education. In D. Kirk, M. O’Sullivan and D. Macdonald (ed.) Handbook of Physical Education, (p163-187) (London, Sage).

U.S. Department of Education (2001) Physical Education for Progress Act (Washington, U.S Congress).

van Kreiken, R. (1998) Norbert Elias (London, Routledge).

Waddington, I., Malcolm, D and Green, K. (1997) Sport, Health and Physical Education: A Reconsideration. European Physical Education Review, 3(2).

Ward, L., Cale, L. and Webb, L. (2007) Physical Education Teachers Experiences, Training and Continuing Professional Development in Health-Related Exercise. Australian Association for Research in Education (AARE) Annual Conference, Fremantle, Australia (November).

Webb, L.A. and Quennerstedt, M. (2010). Risky bodies: Health surveillance and teachers' embodiment of health. Manuscript accepted for publication. International Journal of Qualitative Studies in Education. 
1 Youth Sport Trust (n.d) http://www.youthsporttrust.org/page/specialist-

2 sport/index.html Accessed May 18th 2010.

3

4

5

6

7

8

9

10

11

12

13

14

15

16

17

18

19

20 
1 Table 1. The physical education teachers' experiences of HRE

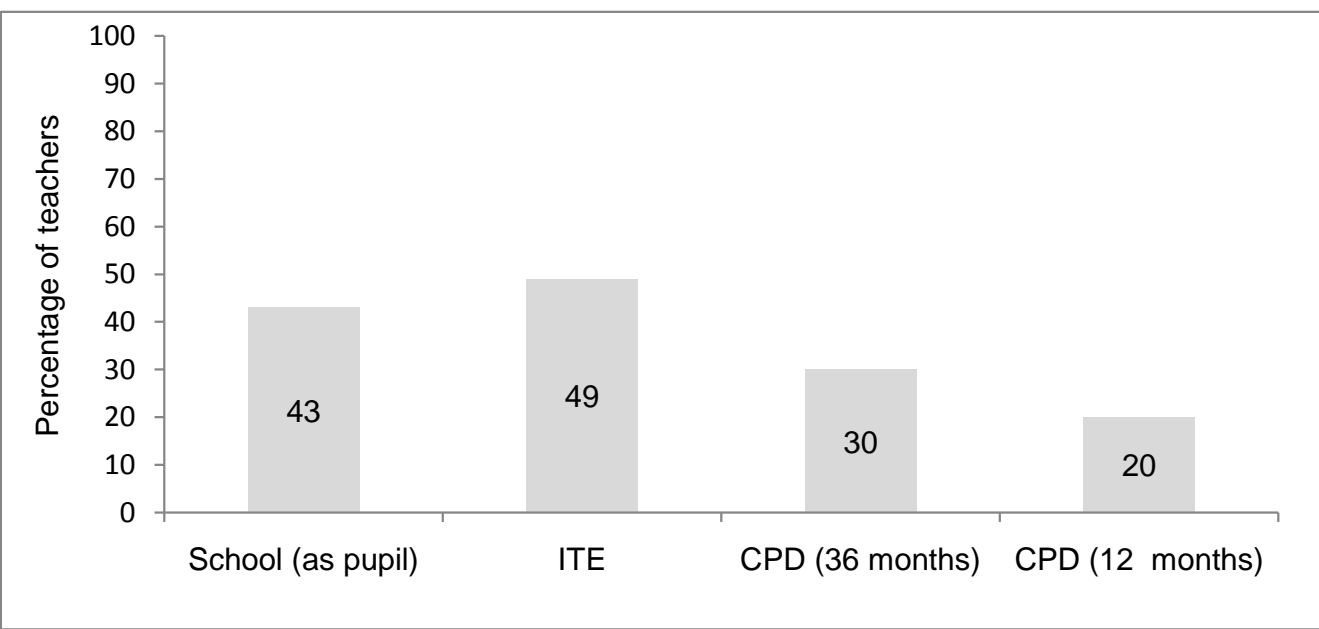

2

4

5

6

7

8

9

10

11

12

13

14

15

16

17

18

19 
1 Figure 1: The HRE Conundrum

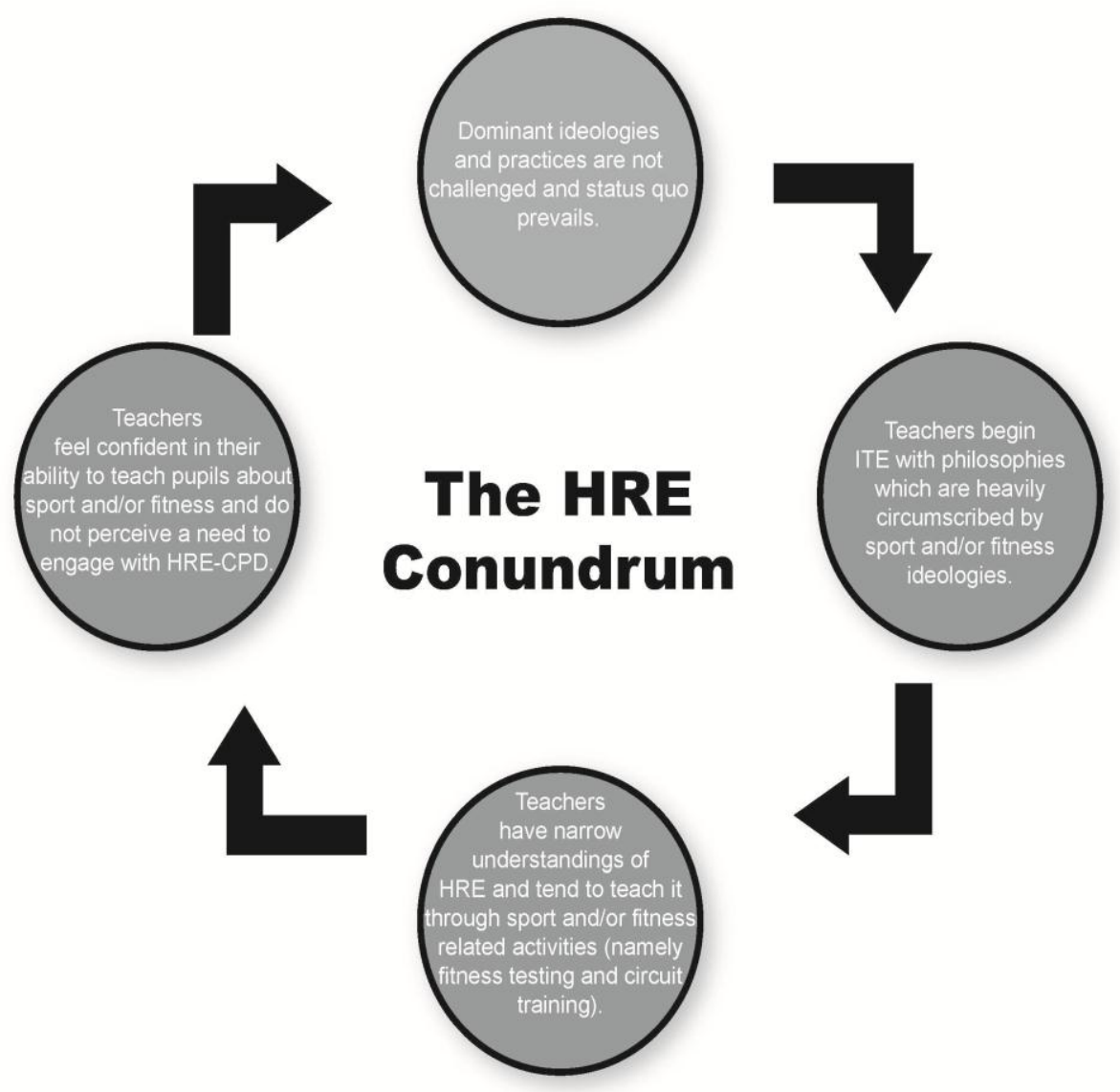

2

3

4

5

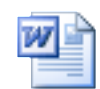

PESP_2010-0093_Co

6

nundrum_Response_1 